\title{
Adaptação do Inventário do Clima Familiar para Crianças (ICF-C)
}

\author{
Neyfsom Carlos Fernandes Matias ${ }^{1}$, Maycoln Leoni Martins Teodoro \\ Universidade Federal de Minas Gerais, Belo Horizonte, MG, Brasil
}

RESUMO

O artigo apresenta o processo de adaptação do Inventário do Clima Familiar para Crianças (ICF-C). A escala foi aplicada em uma amostra de 183 crianças com idades entre 8 e 12 anos e foram investigadas as diferenças relativas à escola, ao ano escolar e ao sexo. $\mathrm{O}$ ICF-C apresentou índices psicométricos adequados com índice Kaiser-Meyer-Olkin igual a 0,77 e teste de esfericidade de Bartlett significativo $\left(\chi^{2}=741,70 ; g l=210, p<0,001\right)$. Foi identificada diferença $(p<0,05)$ no clima negativo entre os participantes divididos por escolas. O instrumento mostra-se como uma ferramenta útil na investigação do clima familiar a partir das crianças e pode ser usado em intervenções e pesquisas com o público infantil.

Palavras-chave: relações familiares; psicometria; inventário; autoavaliação.

\section{ABSTRACT - Adapting the Family Climate Inventory for Children}

The article presents the adaptation process of the Family Climate Inventory for Children (FCI-C). The scale was applied in a sample of 183 children from 8 to 12 years of age, and differences related to the school type, grade level and sex were investigated. The FCI-C presented adequate psychometric indexes with Kaiser-Meyer-Olkin equal to 0.77 and significant Bartlett's sphericity test $\left(\chi^{2}=741.70\right.$; $g l=210, p<0.001)$. There was a difference $(p<0.05)$ in the negative climate among the participants divided by schools. The instrument is useful in researching the family climate from children and can be used in interventions and research with children.

Keywords: family relationships; psychometry; inventory; self-evaluation.

\section{RESUMEN - Adaptación del Inventario de Clima familiar para Niños (ICF-C)}

El artículo presenta el proceso de adaptación del inventario de clima familiar para niños (ICF-C). La escala se aplicó en una muestra de 183 niños con edades comprendidas entre 8 y 12 años, y se investigaron las diferencias relativas a escuela, año escolar y sexo. El ICF-C presentó índices psicométricos adecuados con el índice de Kaiser-Meyer-Olkin igual a 0,77 y el test de esfericidad de Bartlett significativo $\left(\chi^{2}=741,70 ; g l=210, p<0,001\right)$. Se identificó diferencia $(p<0,05)$ en el clima negativo entre los participantes divididos por escuelas. El instrumento se presenta como una herramienta útil en la investigación de clima familiar a partir de los niños y puede ser utilizado en intervenciones e investigaciones con ese tipo de público.

Palabras clave: relaciones familiares; psicometría; inventario; autoevaluación.

Apesar das transformações que a instituição familiar tem passado, não há dúvidas acerca da importância dela sobre o desenvolvimento humano. As interações entre as pessoas nesse grupo, quando vinculadas ao afeto, à proteção e ao desenvolvimento da autonomia das crianças, contribuem para que elas consigam enfrentar as vicissitudes da vida, promovem a aprendizagem de conteúdos escolares (Espósito, Davis, \& Nunes 2000; Marturano, 1999; Marturano \& Elias, 2016; Soares \& Collares, 2006) e fazem com que elas sejam menos suscetíveis a psicopatologias (Boyd \& Bee, 2011; Costa, Cia, \& Barham, 2007; Hauck et al., 2006; Papalia, Olds, \& Feldman, 2009). De maneira contrária, o núcleo familiar também colabora para o aparecimento de problemas socioemocionais quando os conflitos são constantes (Cruvinel \& Boruchovitch, 2009; Cruz \& Abreu-Lima, 2012; Mombelli, Costa, Marcon, \& Moura, 2011; Teodoro, Cardoso, \& Freitas, 2010). Nesse sentido, a família constitui-se como contexto de extrema relevância, com implicações na formação do público infantil (Avanci, Assis, \& Oliveira, 2008; Ferriolli, Marturano, \& Puntel, 2007; Marturano \& Elias, 2016; Pacheco, Souza, \& Teodoro, 2012; Zavaschi et al., 2002).

A maneira como as pessoas vivenciam as interações junto a esse grupo associa-se a variáveis psicossociais ao longo da vida (Ferriolli et al., 2007). O nível socioeconômico, a presença de familiares com doenças crônicas

${ }^{1}$ Endereço para correspondência: Departamento de Psicologia, Praça Dom Helvécio, 74, sala 2.14, Dom Bosco, 36301-160, Belo Horizonte, MG. Tel.: (32) 3379-5185. E-mail: neyfsom@yahoo.com.br 
e o clima familiar, por exemplo, são questões que interferem na relação entre os membros de uma família. A partir disso, este artigo, entre os diversos aspectos existentes, tem como foco o clima familiar. Este corresponde à forma como as pessoas percebem as relações entre os membros da sua família, no que se refere à organização, controle do sistema, crescimento pessoal e aos relacionamentos estabelecidos nesse grupo (Teodoro, Allgayer, \& Land, 2009). Instrumentos que visam a caracterizar esse clima proporcionam informações importantes acerca de possíveis influências no comportamento infantil.

Segundo Loos e Cassemiro (2010), o clima instalado no lar relaciona-se ao desenvolvimento da autoestima e da autoeficácia. Nas famílias em que o clima é marcado por alto nível de comunicações negativas, observa-se a existência de comportamentos entre os familiares comprometedores do envolvimento escolar da criança, diminuindo seu status intelectual e as crenças acerca das suas capacidades. Santana e Cerqueira-Santos (2014), por meio de um estudo com estudantes do ensino fundamental, corroboraram parte dessas informações ao demonstrar a correlação positiva entre clima familiar e clima escolar. Esses dados confirmam as informações de D'Avila-Bacarji, Maturano e Elias (2005) de que questões vinculadas à família, por exemplo, o suporte parental - marcado por apoio ou por conflitos - vinculam-se tanto a problemas escolares como ao desenvolvimento infantil saudável. Nesse sentido, levantamentos relacionados à percepção das interações familiares vêm se destacando, a fim de identificar variáveis que promovem ou prejudicam o desenvolvimento humano (Hess, Teodoro, \& Falcke, 2013; Teodoro, Hess, Saraiva, \& Cardoso, 2014; Sbicigo \& Dell'Aglio, 2012, 2013). No entanto, instrumentos de medidas que contemplem esse aspecto no contexto brasileiro são escassos, principalmente os destinados ao público infantil (Teodoro et al., 2010). Este trabalho tem como meta preencher parte dessa lacuna a partir do Inventário do Clima Familiar (ICF) (Teodoro et al., 2009).

A realização deste estudo pauta-se no fato do instrumento já ter se apresentado como profícuo em pesquisas com adolescentes no intuito de investigar relações entre clima familiar com os seguintes aspectos: problemas emocionais e comportamentais (Hess et al., 2013; Teodoro et al., 2014), envolvimento com atividades ilícitas e consumo de álcool (Sbicigo \& Dell'Aglio, 2012; 2013). O ICF também se mostra adequado para adultos, por exemplo, na análise de interferências do clima familiar no desencadeamento de problemas comportamentais de crianças (Freitas, Siquara, \& Cardoso, 2013). O inventário já foi utilizado em diferentes regiões do Brasil. Sua aplicação tem se limitado ao contexto brasileiro em virtude da ausência de estudos de validação e adaptação para outros países.

A partir de trabalhos que utilizaram o ICF e avaliaram sua consistência interna, por meio do alfa de Cronbach, observam-se bons índices, tais escores nos quatro fatores avaliados pelo inventário (coesão, apoio, conflito e hierarquia), variam de 0,67 a 0,82 (Hess et al., 2013; Sbicigo \& Dell'Aglio, 2012). No estudo de Sbicigo e Dell'Aglio (2013), esse resultado para o total de itens foi de 0,86 . Essas informações destacam a relevância do instrumento. A adequação desse teste para o público infantil contribuirá no acesso ao clima familiar pela ótica das crianças.

A investigação de aspectos familiares é de extrema importância tanto para a clínica infantil como para o desenvolvimento de pesquisas com crianças. Ferramentas voltadas para a família são essenciais no sentido de oferecer dados das interações familiares que possam impactar no desenvolvimento global ao longo da infância (Araújo, 2007; Baptista, Teodoro, Cunha, Santana, \& Carneiro, 2009). Assim, este estudo investigou as propriedades psicométricas do ICF destinado a adolescentes e adultos (Teodoro et al., 2009) junto ao público infantil. Após as análises, o instrumento foi nomeado de Inventário do Clima Familiar para Crianças (ICF-C).

O ICF-C avalia a percepção do clima familiar em dois distintos fatores: clima familiar negativo e clima familiar positivo. Os objetivos deste trabalho foram a adaptação desse instrumento para o público infantil e a análise de algumas de suas propriedades psicométricas. Precisamente, o estudo teve como foco a estrutura fatorial, a consistência interna do inventário e a identificação de diferenças nas percepções do clima familiar no que se refere ao sexo, ao ano de escolarização e às escolas frequentadas pelas crianças. Espera-se com este trabalho, bem como com o ICF-C, contribuir no desenvolvimento de novas investigações sobre o clima familiar e que o inventário seja útil nas intervenções com crianças, sobretudo na compreensão das implicações do clima familiar em questões como bem-estar, problemas cognitivos, comportamentais e escolares.

\section{Método}

\section{Participantes}

Participaram deste estudo 183 crianças de duas escolas públicas municipais das regiões Centro-Sul e Leste de Belo Horizonte (MG). Todos estavam matriculados no segundo ciclo de formação humana, nos anos $4^{\circ}, 5^{\circ}$ e $6^{\circ}$ de escolaridade. A amostra se constituiu com 105 $(57,4 \%)$ participantes do sexo feminino e $78(42,6 \%)$ do sexo masculino. A idade deles variou entre 8 e 12 anos, com média de 10,41 anos $(D P=0,80)$.

\section{Adaptação dos Itens do Inventário do Clima Familiar para Crianças (ICF-C)}

O ICF tem como fundamento teórico as características familiares apresentadas por Björnberg e Nicholson (2007), a elaboração de seus itens considerou instrumentos internacionais e concepções teóricas dos fatores investigados. Esse inventário, desenvolvido por Teodoro, 
Allgayer e Land (2009), e destinado a adolescentes e adultos, possui 22 frases, dispostas em um quadro precedido pela sentença "Em minha família...", divididas em quatro construtos: conflito, hierarquia, apoio e coesão. Os itens são dispostos em escala Likert, de 1 a 5 , em que o respondente tem que indicar o quanto concorda com as frases apresentadas (1 - não concordo de jeito nenhum; 2 - concordo um pouco; 3 - concordo mais ou menos; 4 - concordo muito; e 5 - concordo plenamente).

O fator conflito se refere a relações agressivas, conflituosas e críticas entre as pessoas da família (ex., "As pessoas criticam umas às outras frequentemente"). $\mathrm{Na}$ dimensão hierarquia, pesquisa-se a definição clara de quem detém o poder dentro da família, considerando-se que os mais velhos possuem maior influência e controlam o sistema (ex., "Os mais velhos mandam mais"). Já o construto apoio contempla itens que demonstram suporte emocional e material dentro da família (ex., "Ajudamos financeiramente uns aos outros"). E, por fim, a coesão define-se como a vinculação emocional entre os membros do núcleo familiar (ex., "As pessoas gostam umas das outras") (Teodoro et al., 2009).

A primeira etapa de adaptação do ICF para crianças contemplou um processo de simplificação e reescrita dos itens. Foram realizadas duas estratégias. A primeira consistiu na avaliação pelo público-alvo e se deu por meio da aplicação da versão original do ICF em cinco crianças. Essa etapa teve o objetivo de verificar a clareza das instruções, se os termos estavam adequados e em sintonia com as expressões utilizadas pelas crianças com o intuito de garantir a compreensão de todos os itens (Borsa, Damásio, \& Bandeira, 2012). Após a aplicação, o primeiro autor desta pesquisa discutiu com o grupo sobre a compreensão de cada item e se haviam entendido o que foi perguntado. Alguns itens foram identificados, pelos estudantes, como de difícil compreensão. A Tabela 1 apresenta os itens que compõem o ICF e quais foram apontados como incompreensíveis.

Tabela 1

Itens do Inventário do Clima Familiar para Adolescentes e Adultos

1. Procuramos ajudar as pessoas da nossa família quando percebemos que estão com problemas.*

2. As proibições são constantes.

3. Uns mandam e outros obedecem.

4. As pessoas zombam umas das outras.

5. Briga-se por qualquer coisa.*

6. Algumas pessoas deixam de fazer as suas coisas para auxiliar as outras pessoas da família.*

7. Não importa a vontade da maioria, a decisão final é sempre da mesma pessoa.*

8. As pessoas irritam umas às outras.

9. As pessoas gostam de passear e de fazer coisas juntas.

10. As pessoas resolvem os problemas brigando.

11. As pessoas criticam umas às outras frequentemente.*

12. Resolver problemas significa discussão e brigas.*

13. As pessoas tentam ajudar umas às outras quando as coisas não vão bem.

14. As pessoas gostam umas das outras.

15. Sinto que existe união entre os membros.*

16. Os mais velhos mandam mais.*

17. As pessoas se sentem próximas umas das outras.

18. O(s) filho(s) tem(têm) pouco poder nas decisões familiares.*

19. Temos prazer e alegria em passar o tempo juntos.*

20. Algumas pessoas resolvem os problemas de maneira autoritária.*

21. Ajudamos financeiramente uns aos outros.

22. As pessoas me ajudam a fazer as coisas quando não tenho tempo.

Nota. *Item apontado como difícil de compreender pelas crianças

A segunda estratégia, realizada simultaneamente, contou com a reescrita dos itens por duas pesquisadoras da área de instrumentos psicológicos e da psicologia infantil. Elas indicaram as mesmas necessidades de alterações destacadas pelos cinco respondentes. Com isso, realizaram-se modificações nos itens 1, 5, 6, 7, 11, 12, 15, 16, 18, 19 e 20. O item 21 (Ajudamos financeiramente uns aos outros) foi retirado. Assim, chegou-se à versão aplicada no presente estudo. Na Tabela 3, encontram-se os itens que compuseram a versão utilizada na coleta de dados. 
Tabela 2

Itens do Inventário do Clima Familiar Adaptados para a Realização do Estudo

1. Ajudamos as pessoas da nossa família quando elas estão com problemas.

2. As proibições são constantes.

3. Uns mandam e outros obedecem.

4. As pessoas zombam umas das outras.

5. Qualquer coisa é motivo de brigas.

6. Algumas pessoas deixam de fazer as suas coisas para ajudar as outras pessoas da família.

7. Não importa a vontade de ninguém, a decisão final é sempre da mesma pessoa.

8. As pessoas irritam umas às outras.

9. As pessoas gostam de passear e de fazer coisas juntas.

10. As pessoas resolvem os problemas brigando.

11. As pessoas criticam umas às outras toda a hora.

12. Os problemas são sempre resolvidos com discussões e brigas.

13. As pessoas tentam ajudar umas às outras quando as coisas não vão bem.

14. As pessoas gostam umas das outras.

15. Existe união entre as pessoas.

16. Os mais velhos mandam mais do que os mais novos.

17. As pessoas se sentem próximas umas das outras.

18. O(s) filho(s) manda(m) pouco.

19. Gostamos de passar o tempo juntos.

20. Algumas pessoas resolvem os problemas mandando nas outras.

21. As pessoas me ajudam a fazer as coisas quando não tenho tempo.

\section{Procedimentos}

O trabalho de coleta de dados foi iniciado após aprovação do projeto pelo Comitê de Ética da Universidade Federal de Minas Gerais (Parecer n . 389.787) e ocorreu em duas escolas municipais. Por meio de visitas às salas de aula, todos os estudantes matriculados no $4^{\circ}, 5^{\circ}$ e $6^{\circ}$ anos foram convidados a participar do estudo. Aqueles que concordaram levaram o Termo de Consentimento Livre e Esclarecido para a assinatura de seus responsáveis. $\mathrm{O}$ instrumento foi aplicado de forma coletiva, em grupos compostos por sete a 10 estudantes, em salas disponibilizadas pelas escolas e conduzidas pelo primeiro autor deste estudo com dois auxiliares. As instruções de preenchimento foram dadas de forma oral, escritas no quadro-negro, junto com as frases e números correspondentes. A explicação de como preencher a escala Likert era acompanhada das seguintes instruções:

"Este questionário trata de um tema muito importante que temos muito a dizer: a nossa família. Nós gostaríamos de que vocês pensassem sobre as pessoas das famílias de vocês antes de responder a cada pergunta. $\mathrm{Na}$ folha que receberam tem uma frase logo acima: 'Em minha família...' e abaixo várias frases. Vocês vão ler a frase de cima e completar com as que estão abaixo e marcar uma das opções que estão à frente de acordo com o que acontece na casa de vocês. Por exemplo: 'Em minha família, ajudamos as pessoas da nossa família quando elas estão com problemas'. Vocês vão marcar (1) não concordo de jeito nenhum; (2) concordo um pouco; (3) concordo mais ou menos; (4) concordo muito, e (5) concordo plenamente. Cada um responde a sua folha e não tem resposta certa ou errada. Nós queremos saber o que pensam sobre a família de vocês. Se tiverem dúvida é só levantar a mão".

\section{Análise dos Dados}

De início, foram levantadas as frequências das respostas, com o intuito de identificar a ocorrência de ausência de respostas. Todos os itens tiveram mais de $90 \%$ de preenchimento. Nos casos omissos, optou-se pela utilização da média do item. Não foram destacados sujeitos que omitiram mais de $10 \%$ das respostas, então, nenhum participante foi eliminado da amostra. Em seguida procedeu-se às análises, em duas etapas.

$\mathrm{Na}$ primeira, foi realizada uma análise fatorial exploratória a partir do estimador Unweighted Least Squares (ULS) por meio de uma matriz de correlações policóricas. Esses procedimentos são os mais recomendados para itens cujas respostas são de caráter ordinal, como é o caso das escalas do tipo Likert (Asún, Rdz-Navarro, \& Alvarado, 2015). Para a retenção dos fatores, foi utilizado a análise paralela com permutação dos dados empíricos (Damásio, 2012; Timmerman \& Lorenzo-Seva, 2011). Os quatro construtos do ICF desenvolvidos teoricamente serviram de base para a seleção dos fatores. Contudo, resultados do método de Kaiser e o gráfico de sedimentação contribuíram na decisão do número de construtos e interpretação dos resultados. Para investigar a consistência interna do instrumento, segunda etapa da análise, utilizou-se o alfa de Cronbach, e as relações entre os fatores foram investigadas pela correlação de Pearson. 
Após essas duas fases, foram investigadas diferenças nos resultados por sexo e por escola, com o teste de Mann-Whitney e, por ano de escolarização, a partir do teste de Kruskal-Wallis. As análises se deram nos programas estatísticos Factor 10.5.02 (Lorenzo-Seva \& Ferrando, 2013) e Statistical Package for the Social Sciences (SPSS), versão 18. O nível de significância adotado foi de $p<0,05$.

\section{Resultados}

\section{Análises Fatoriais Exploratórias do Inventário do Clima Familiar para Crianças (ICF-C)}

A versão inicial do ICF-C era composta por 21 itens divididos entre os quatro fatores, de acordo com o modelo do ICF para adolescentes e adultos. Os resultados da análise paralela indicaram que dois autovalores superaram a variância explicada, pelo percentil 95, pela distribuição aleatória dos autovalores. Ou seja, a estrutura do ICF não se confirmou no ICF-C e foram retidos 18 itens que se dividiram em dois fatores, denominados de clima familiar negativo e clima familiar positivo. Os resultados do índice Kaiser-Meyer-Olkin (KMO) foi igual a 0,77 e do teste de esfericidade de Bartlett foi significativo $\left(\chi^{2}=741,70 ; g l=210, p<0,001\right)$, indicando uma adequação dos dados. Com isso, a versão final do ICF-C possui 18 itens, divididos em dois fatores, como descrito na Tabela 3.

As análises de consistência interna dos dois fatores, realizadas pelo alfa de Cronbach, resultaram nos escores para clima familiar negativo 0,77 e clima familiar positivo 0,67. O alfa Cronbach do total de itens o ICF-C calculado, invertendo-se os valores do fator negativo, foi de 0,77 . A inversão ocorreu devido aos resultados das análises de correlação de Pearson entre os dois fatores, que indicou associação fraca entre clima familiar negativo e clima familiar positivo $(r=-0,32 ; p<0,001)$.

Tabela 3

Cargas Fatoriais, Variância Explicada e Alfas de Cronbach para os Escores do ICF-C

\begin{tabular}{|c|c|c|}
\hline \multirow{2}{*}{ Itens } & \multicolumn{2}{|c|}{ Cargas fatoriais } \\
\hline & Negativo & Positivo \\
\hline As pessoas resolvem os problemas brigando. & 0,91 & \\
\hline As pessoas criticam umas às outras toda a hora. & 0,71 & \\
\hline Algumas pessoas resolvem os problemas mandando nas outras. & 0,67 & \\
\hline As pessoas irritam umas às outras. & 0,66 & \\
\hline Qualquer coisa é motivo de brigas. & 0,61 & \\
\hline As pessoas zombam umas das outras. & 0,59 & \\
\hline Os problemas são sempre resolvidos com discussões e brigas. & 0,57 & \\
\hline Não importa a vontade de ninguém, a decisão final é sempre da mesma pessoa. & 0,40 & \\
\hline As pessoas tentam ajudar umas às outras quando as coisas não vão bem. & & 0,72 \\
\hline Existe união entre as pessoas. & & 0,68 \\
\hline As pessoas gostam de passear e de fazer coisas juntas. & & 0,67 \\
\hline As pessoas se sentem próximas umas das outras. & & 0,66 \\
\hline As pessoas me ajudam a fazer as coisas quando não tenho tempo. & & 0,51 \\
\hline As pessoas gostam umas das outras. & & 0,48 \\
\hline Algumas pessoas deixam de fazer as suas coisas para ajudar as outras pessoas da família. & & 0,38 \\
\hline Ajudamos as pessoas da nossa família quando elas estão com problemas. & & 0,34 \\
\hline Gostamos de passar o tempo juntos. & & 0,33 \\
\hline Os mais velhos mandam mais do que os mais novos. & & 0,32 \\
\hline Variância explicada & 26,02 & 37,35 \\
\hline Alfa de Cronbach & 0,77 & 0,67 \\
\hline
\end{tabular}

Nota. ICF-C=Inventário do Clima Familiar para Criança

\section{Diferenças quanto ao Sexo, Ano de Escolarização e Escola de Origem no ICF-C}

As análises realizadas a partir do teste de MannWhitney demonstram diferença significativa no fator negativo na comparação entre as escolas. Os alunos da escola municipal 2 (EM 2) apresentaram postos mais altos no fator negativo em relação à escola municipal 1 (EM 1). Não houve diferença significativa entre os participantes divididos por sexo, no clima negativo $(p=0,313)$, no clima positivo $(p=0,737)$ e no total do ICF-C $(p=0,366)$. Nas comparações por ano de escolarização, também não houve significância estatística no clima 
negativo $(p=0,676)$, no clima positivo $(p=0,846)$ e no total do ICF-C $(p=0,353)$. Os resultados das análises do teste de Mann-Whitney entre as duas escolas, bem como as medianas, médias, desvios padrão e percentis estão descritos na Tabela 4.

Tabela 4

Média, Desuios Padrões e Percentis dos Escores do ICF-C nas Escolas 1 e 2

\begin{tabular}{|c|c|c|c|c|c|c|c|c|}
\hline \multirow{2}{*}{ ICF-C } & \multirow{2}{*}{ Escola } & \multirow{2}{*}{$\mathrm{Md}$} & \multirow{2}{*}{ Média (DP) } & \multicolumn{3}{|c|}{ Percentis } & \multirow{2}{*}{ Teste U } & \multirow{2}{*}{$P$} \\
\hline & & & & 25 & 50 & 75 & & \\
\hline Negativo & $\begin{array}{l}\text { EM } 1 \\
\text { EM } 2\end{array}$ & $\begin{array}{l}13,00 \\
16,00\end{array}$ & $\begin{array}{l}14,78(5,66) \\
17,22(6,80)\end{array}$ & $\begin{array}{l}10,00 \\
12,00\end{array}$ & $\begin{array}{l}13,00 \\
16,00\end{array}$ & $\begin{array}{l}19,00 \\
22,25\end{array}$ & 3088,500 & 0,015 \\
\hline Positivo & $\begin{array}{l}\text { EM } 1 \\
\text { EM } 2\end{array}$ & $\begin{array}{l}42,00 \\
41,00\end{array}$ & $\begin{array}{l}41,06(5,68) \\
40,54(5,77)\end{array}$ & $\begin{array}{l}36,45 \\
36,68\end{array}$ & $\begin{array}{l}42,00 \\
41,00\end{array}$ & $\begin{array}{l}45,50 \\
45,00\end{array}$ & 3736,500 & 0,571 \\
\hline Clima Total & $\begin{array}{l}\text { EM } 1 \\
\text { EM } 2\end{array}$ & $\begin{array}{l}55,03 \\
57,58\end{array}$ & $\begin{array}{l}55,84(5,98) \\
57,76(7,69)\end{array}$ & $\begin{array}{l}52,00 \\
54,00\end{array}$ & $\begin{array}{l}55,03 \\
57,58\end{array}$ & $\begin{array}{l}59,00 \\
63,00\end{array}$ & 3171,500 & 0,028 \\
\hline
\end{tabular}

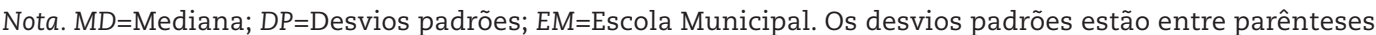

\section{Discussão}

O objetivo deste estudo foi investigar propriedades psicométricas do ICF para crianças. Precisamente, buscou-se desenvolver um instrumento de autorrelato que proporcionasse a identificação do clima familiar percebido pelas crianças. Não foram encontrados os mesmos fatores no ICF-C pertencentes ao instrumento de origem. Os itens que restaram, dos 21 iniciais, dividiram-se em dois polos distintos e não satisfizeram à expectativa de quatro fatores. A análise semântica dos itens sugere o primeiro fator como um clima familiar negativo, caracterizado por críticas, brigas e autoritarismo. Nele estão presentes oito itens, que corresponde a $26,02 \%$ da variância da escala, dos quais seis se referem ao fator conflito e dois do fator hierarquia no ICF e justifica considerá-lo como clima familiar negativo. O segundo demonstra um clima positivo, marcado pelo auxílio e união dos membros, com 10 itens e explica 37,35\% da variância, dos quais quatro são do fator apoio, cinco do construto coesão e um do fator hierarquia do ICF. Análises por meio do teste de Mann-Whitney não indicaram diferença significativa quanto ao sexo, bem como no teste de Kruskal-Wallis em relação aos anos de escolarização dos participantes. Porém, houve significância estatística nas análises entre as duas escolas no fator negativo. Esses resultados têm aspectos importantes a serem discutidos.

Contrário ao que se esperava, a análise fatorial apontou dois fatores no instrumento, em vez de quatro. A explicação para esse resultado pode ser atribuída à faixa etária dos participantes, que tinha idade média de 10,41 anos. Nesse período, as percepções sobre os relacionamentos ainda se encontram em estágios de aprimoramento. Especificamente, crianças nessa fase descrevem pessoas por meio de explicações que se remetem mais aos comportamentos apresentados por elas do que aos aspectos cognitivos (Barenboim, 1981; Boyd \& Bee, 2011).
Assim, a redução a dois fatores pode ser resultado de uma tendência dos participantes de ainda não relacionarem aspectos psicológicos com comportamentos nas descrições de suas percepções (Flavell, Miller, \& Miller, 1999). Ao se observarem os 18 itens, nota-se que a maioria faz mais referência a questões comportamentais - brigar, criticar, irritar, zombar, mandar, passear - do que cognitivas - união, sentir, gostar. É preciso considerar que a ausência de escalas com o mesmo foco para crianças coloca empecilhos para explicações mais precisas. Além disso, segundo Barenboim (1981), espera-se que as crianças comecem a utilizar construtos psicológicos para descrever suas percepções por volta dos 10 anos, ou seja, a amostra encontrava-se no início do desenvolvimento desta habilidade cognitiva (Flavell et al., 1999). Devido a essas questões, a alteração dos itens, a partir da entrevista com as crianças e reescrita pelas especialistas, foi essencial para alcançar os objetivos do estudo.

Ainda como efeito do período desenvolvimental da amostra, é preciso considerar a percepção dos dois itens do fator hierarquia, retidos no fator negativo, com conotações opressivas: "Algumas pessoas resolvem os problemas mandando nas outras" e "Não importa a vontade de ninguém, a decisão final é sempre da mesma pessoa". Eles remetem ao fato das crianças perceberem os membros mais velhos das suas famílias como opressores. Ou seja, esses itens indicam a possibilidade da identificação da coação adulta como parte do clima familiar (Piaget, 1994). Nesse sentido, mantê-los no fator negativo é coerente. Mas isso não se aplica ao item do mesmo fator do ICF inserido no clima positivo: "Os mais velhos mandam mais do que os mais novos". Essa visão da autoridade dos mais velhos faz parte do pensamento de crianças no período etário em que as participantes do estudo estavam e é importante no desenvolvimento do juízo moral (Piaget, 1994). Logo, sua manutenção no fator positivo é pertinente. 
Os dois fatores apurados nas análises possuem itens relacionados aos quatro fatores do ICF. Os índices de variância explicada e magnitude das cargas fatoriais sugerem bons índices do instrumento (Pasquali, 2011). Os baixos valores do alfa Cronbach dos construtos negativo $(0,77)$ e positivo $(0,67)$ podem ser atribuídos ao número de itens de cada um, respectivamente, 8 e 10.

Quanto ao sexo, não se destacou diferença entre meninos e meninas. O estudo de desenvolvimento e validação do ICF para adolescentes também não encontrou discrepância quanto a esse aspecto (Teodoro et al., 2009). No estudo de Barenboim (1981), acerca dos aspectos do desenvolvimento da percepção de crianças, também não se evidenciou diferença significativa nesse sentido.

Houve significância estatística entre as escolas no fator clima familiar negativo. A EM 2 apresentou postos mais altos, medianas e médias superiores à da EM 1, o que indica que os estudantes dessa instituição percebem o clima familiar com características mais negativas, ou seja, eles indicam que o clima das suas famílias é marcado por críticas e brigas. A única informação acessada sobre variáveis sociais relacionadas às famílias é a do nível socioeconômico das escolas, sendo que a EM 1 possui índice menor do que a EM $2^{2}$. No entanto, as duas estavam com nível socioeconômico considerado baixo pela Secretaria Municipal de Educação $(<2,00)$. Devido a isso e à literatura sobre as implicações do baixo poder aquisitivo nas relações familiares (Cruz \& Abreu-Lima
2012), esperava-se resultado contrário ao encontrado, isto é, que a escola EM 1 demonstrasse índice maior do que a EM 2 no fator negativo. No estudo do ICF para adolescentes, houve diferença entre as escolas pública e particular, que pode ser atribuída à questão econômica das famílias. Os autores ressaltam que, por não haver informações acerca do nível socioeconômico dos participantes, é preciso ter ressalvas quanto a esse dado (Teodoro et al., 2009). Em resumo, não se pode atribuir à questão socioeconômica a causa da diferença no clima familiar negativo entre as escolas no presente estudo.

Espera-se que o ICF-C contribua na busca de informações acerca do clima familiar. Por ser instrumento de autorrelato, ele se mostra como de grande utilidade, devido às dificuldades de acesso aos responsáveis pelas crianças em pesquisas realizadas em instituições de ensino. Novos estudos, desenvolvidos em outras regiões, correlacionando os escores do ICF-C com construtos como habilidades sociais, bem-estar subjetivo e depressão infantil devem ser realizados, a fim de se obterem dados sobre o instrumento e contribuir para o seu aperfeiçoamento. Torna-se pertinente a realização de novas investigações com participantes de estrato social diferente do apresentado pela amostra. Além disso, é necessária a realização, em investigações futuras, de análise fatorial confirmatória, a fim de identificar sua adequação aos dados empíricos.

\section{Referências}

Araújo, M. F. (2007). Estratégias de diagnóstico e avaliação psicológica. Psicologia: Teoria e Prática, 9(2), 126-141. Recuperado de http://pepsic. bvsalud.org/pdf/ptp/v9n2/v9n2a08.pdf

Asún, R. A., Rdz-Navarro, K., \& Alvarado, J. M. (2015). Developing multidimensional Likert Scales using item factor analysis: The case of four-point items. Sociological Methods E Research, 45(1), 109-133. doi: 10.1177/0049124114566716

Avanci, J. Q., Assis, S. G., \& Oliveira, R. V. C. (2008). Sintomas depressivos na adolescência: estudo sobre fatores psicossociais em amostra de escolares de um município do Rio de Janeiro, Brasil. Cadernos de Saúde Pública, 24(10), 2334-2346. doi: 10.1590/S0102311X2008001000014

Baptista, M. N., Teodoro, M. L. M., Cunha, R. V. da, Santana, P. R., \& Carneiro, A. M. (2009). Evidência de validade entre o inventário de percepção de suporte familiar - IPSF e Familiograma FG. Psicologia Reflexão e Crítica, 22(3), 466-473. doi: 10.1590/S010279722009000300018

Barenboim, C. (1981). The development of person perception in childhood and adolescence: From behavioral comparisons to psychological constructs to psychological comparisons. Child Development, 52(1), 129-144. doi: 10.2307/1129222

Björnberg, Å., \& Nicholson, N. (2007). The family climate scales - Development of a new measure for use in family business research. Family Business Review, 20(3), 229-246. doi: 10.1111/j.1741-6248.2007.00098.x

Borsa, J. C., Damásio, B. F., Bandeira, D. R. (2012). Adaptação e validação de instrumentos psicológicos entre culturas: algumas considerações. Paidéia, 22(53), 423-432. doi: 10.1590/S0103-863X2012000300014

Boyd, D., \& Bee, H. (2011). A criança em crescimento. (Trad. D. Bueno). Porto Alegre: Artmed.

Costa, C. S. L., Cia, F., \& Barham, E. J. (2007). Envolvimento materno e desempenho acadêmico: comparando crianças residindo com a mãe e com ambos os pais. Revista Semestral da Associação Brasileira de Psicologia Escolar e Educacional, 11(2), 339-351. doi: 10.1590/S141385572007000200012

Cruvinel, M., \& Boruchovitch, E. (2009). Sintomas de depressão infantil e ambiente familiar. Psicologia em Pesquisa-UFJF, 3(1), 87-100. Recuperado de http://pepsic.bvsalud.org/pdf/psipesq/v3n1/v3n1a08.pdf

\footnotetext{
${ }^{2}$ Devido ao critério de se manter o anonimato das instituições, optou-se por restringir detalhes acerca desses números.
} 
Cruz, O., \& Abreu-Lima, I. (2012). Qualidade do ambiente familiar - preditores e consequências no desenvolvimento das crianças e jovens. Revista AMAzônica, VIII(1), 246-265. Recuperado de: https://goo.gl/io7JhN

Damásio, B. F. (2012). Uso da análise fatorial exploratória em psicologia. Avaliação Psicológica, 11(2), 213-228. Recuperado de http://pepsic. bvsalud.org/pdf/avp/v11n2/v11n2a07.pdf

D’Avila-Bacarji, K. M. G., Maturano, E. M., \& Elias, L. C. S. (2005). Suporte parental: um estudo sobre crianças com queixas escolares. Psicologia em Estudo, 10(1), 107-115. doi: 10.1590/S1413-73722005000100013

Espósito, Y. L., Davis, C., \& Nunes, M. M. R. (2000). Sistema de avaliação do rendimento escolar. Revista Brasileira de Educação, 13 , 25-53. Recuperado de http://anped.tempsite.ws/novo_portal/rbe/rbedigital/RBDE13/RBDE13_03_YARA_CLAUDIA_E_MARINA.pdf

Ferriolli, S. H. T., Maturano, E. M., \& Puntel, L. P. (2007). Contexto familiar e problemas de saúde mental infantil no Programa Saúde da Família. Revista Saúde Pública, 41(2), 234-253. doi: 10.1590/S0034-89102006005000017

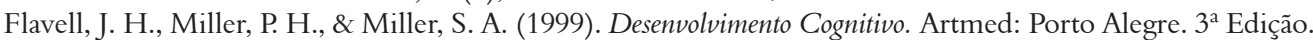

Freitas, P. M., Siquara, G. M., \& Cardoso, T. da S. G. (2013). Percepção das mães sobre as relações familiares e o comportamento de suas crianças: um estudo correlacional. Gerais: Revista Interinstitucional de Psicologia, 6(1), 20-35. Recuperado de http://pepsic.bvsalud.org/pdf/ gerais/v6n1/v6n1a03.pdf

Hauck, S., Schestatsky, S., Terra, L., Knijnik, L., ... Sanchez, P. (2006). Adaptação transcultural para o português brasileiro do Parental Bonding Instrument (PBI). Revista de Psiquiatria, 28(2), 162-168. doi: 10.1590/S0101-81082006000200008

Hess, A. R. B., Teodoro, M. L. M., \& Falcke, D. (2013). Family relations, stressful events and internalizing symptoms in adolescence: A longitudinal study. Spanish Journal of Psychology, 16(57) p. 1-7. doi: 10.1017/sjp.2013.57

Loos, H., \& Cassemiro, L. F. K. (2010). Percepções sobre a qualidade da interação familiar e crenças autorreferenciadas em crianças. Estudos de Psicologia (Campinas) 27(3), 293-303. doi: 10.1590/S0103-166X2010000300002

Lorenzo-Seva, U. \& Ferrando, P. J. (2013). FACTOR 9.2: A comprehensive program for fitting exploratory and semiconfirmatory factor analysis and IRT models. Applied Psychological Measurement, 37(6), 497-498. doi: 10.1177/0146621613487794

Marturano, E. M. (1999). Recursos no ambiente familiar e dificuldades de aprendizagem na escola. Psicologia: Teoria e Pesquisa, 15(2), 135142. doi: 10.1590/S0102-37721999000200006

Marturano, E. M., \& Elias, L. C. dos S. (2016). Família, dificuldades no aprendizado e problemas de comportamento escolares. Educar em Revista, 59, 123-139. doi: 10.1590/0104-4060.44617

Mombelli, M. A., Costa, J. B., Marcon, S. S., \& Moura, C. B. (2011). Estrutura e suporte familiar como fatores de risco de stress infantil. Estudos de Psicologia, 28(3), 327-335. doi: 10.1590/S0103-166X2011000300004

Pacheco, J. T. B., Souza, L. K., \& Teodoro, M. (2012). Avaliação das relações familiares e do comportamento interpessoal de crianças e de adolescentes. Em C. S. Hutz, (Ed.). Avanços em avaliação neuropsicológica de crianças e adolescentes II. (pp. 237-252). Casa do Psicólogo: São Paulo.

Papalia, D. E., Olds, S. W., \& Feldman, R. D. (2009). Desenvolvimento Humano. (Trads. C. F. M. P. Vercesi, D. Catunda, J. C. B. dos Santos, M. de C. Silva). Artmed: São Paulo.

Pasquali, L. (2011). Psicometria: teoria dos testes na Psicologia e Educação. Editora Vozes: Petrópolis. $4^{\text {a }}$ edição.

Piaget, J. (1994). OJuízo moral na criança. (Trad. E. Lenardon). Summus: São Paulo.

Santana, M. V. de M., \& Cerqueira-Santos, E. (2014). Avaliação de ansiedade infanto-juvenil e sua relação com o clima familiar e escolar. Revistas Subjetividades, 14(1), 141-151. Recuperado de http://pepsic.bvsalud.org/pdf/rs/v14n1/13.pdf

Sbicigo, J. B., \& Dell'Aglio, D. D. (2013). Contextual variables associated with psychosocial adjustment of adolescents. Spanish Journal of Psychology, 16(11), 1-10. doi: 10.1017/sjp.2013.20

Soares, J. F., \& Collares, A. C. M. (2006). Recursos familiares e o desempenho cognitivo dos alunos do ensino básico brasileiro. DADOS Revista de Ciências Sociais, 49(3), 615-650. doi: 10.1590/S0011-52582006000300007

Teodoro, M. L. M., Cardoso, B. M. \& Freitas, A. C. F. (2010). Afetividade e conflito familiar e sua relação com a depressão em crianças e adolescentes. Psicologia: Reflexão e Crítica, 23(2), 324-333. doi: 10.1590/S0102-79722010000200015

Teodoro, M. L., Allgayer, M. Land, B. (2009). Desenvolvimento e validade fatorial do clima familiar para adolescentes. Psicologia: Teoria e Prática, 11(3), 27-39. Recuperado de http://pepsic.bvsalud.org/pdf/ptp/v11n3/v11n3a04.pdf

Teodoro, M. L., Hess, A. R. B., Saraiva, L. A., \& Cardoso, B. M. (2014). Problemas emocionais e de comportamento e clima familiar em adolescentes e seus pais. Psico, 45(2), 168-175.

Timmerman, M. E., \& Lorenzo-Seva, U. (2011). Dimensionality assessment of ordered polytomous items with parallel analysis. Psychological Methods, 16(2), 209-220. doi: 10.1037/a0023353

Zavaschia, M. L. S., Satlerb, F., Poesterc, D., Vargasd, C. F., Piazenskib, R., Rohdee, L. A. P., \& Eizirikf, C. L. (2002). Associação entre trauma por perda na infância e depressão na vida adulta. Revista Brasileira de Psiquiatria, 24(4), 189-195. doi: 10.1590/\$1516-44462002000400009

\section{Sobre os autores}

Neyfsom Carlos Fernandes Matias é professor do Departamento de Psicologia da Universidade Federal de São João Del-Rei e doutor em Psicologia do Desenvolvimento Humano, na área de concentração Cognição e Linguagem, pela Universidade Federal de Minas Gerais.

Maycoln Leoni Martins Teodoro é professor do Programa de Pós-Graduação em Psicologia: Cognição e Comportamento da Universidade Federal de Minas Gerais, doutor em Psicologia Clínica e do Desenvolvimento (ALU Freiburg, Alemanha), bolsista produtividade (CNPq) e integrante do Programa Pesquisador Mineiro (Fapemig). 